\title{
Razão, sentido e formação a partir de um diálogo entre Benjamin e Habermas'
}

\author{
Claudia Fenerich"
}

\begin{abstract}
Resumo
0 artigo aborda o tema da formação sob a perspectiva da filosofia, buscando enfrentar o problema de como conferir-lhe, nas atuais condições sociais e de pensamento, um direcionamento ético, moral e político. Com esse foco, a partir de um diálogo entre os pensamentos de Habermas e de Benjamin estabelecido com base em pesquisa bibliográfica, propõe e encaminha as seguintes questões: é possível formar sem transmitir conteúdos éticos, sem compartilhar experiências de vida?; é possível emancipar-se sem atribuir sentido à existência?; qual é a relação entre a razão e o sentido? Uma dupla hipótese orienta a investigação apresentada: a ética, a moral e a política constituem dimensões fundamentais da vida humana, sem as quais não há parâmetro para a formação; a formação para a emancipação depende de uma experiência da liberdade de pensar, criar, expressar e atribuir sentidos que passa, necessariamente, pela vitalização das possibilidades de comunicação entre aqueles que compartilham práticas de vida. A partir da pesquisa realizada, o artigo conclui que, para favorecer a abertura ao outro e fornecer parâmetros para o julgamento moral, autônomo - atitudes fundamentais para a convivência democrática nas sociedades complexas atuais -, a formação não pode prescindir do processo de transmissão de experiências éticas de vida, ainda que isso seja um grande desafio perante a razão secularizada de que dispomos hoje.
\end{abstract}

\section{Palavras-chave}

Razão - Sentido - Formação - Ética.
I- Este texto sintetiza os resultados da pesquisa de pós-doutoramento 0 encontro entre eu e outro na escola: do estranhamento ao entendimento, desenvolvida junto à Pontifícia Universidade Católica do Rio Grande do Sul entre agosto de 2011 e julho de 2012, com apoio do CNPq.

II- Pontifícia Universidade Católica do Rio Grande do Sul, Porto Alegre, RS, Brasil. Contato: claudia.fenerich@gmail.com 


\title{
Reason, meaning and formation building on a dialogue between Benjamin and Habermas'
}

Claudia Fenerich"

\begin{abstract}
This paper addresses formation in the perspective of philosophy, in an attempt to face the problem of how to make sure, under the current social and thinking conditions, an ethical, moral and political guidance is provided with such formation. Focusing on that, building on a dialogue between the thoughts of Habermas and Benjamin established as a result of bibliographical research, the paper proposes and addresses the following issues: is it possible to form (educate) without transmitting ethical contents, without sharing experiences of life?; is it possible to emancipate oneself without assigning meaning to existence?; what is the relationship between reason and meaning? A double assumption orientates the investigation presented herein: ethics, moral and politics are fundamental dimensions of human life, without which there is no parameter for formation; formation for emancipation depends on a experience of the freedom to think, create, express and assign meanings which has necessarily to do with the vitalization of the possibilities of communication between those who share practices of life. Building on the research undertaken, the paper concludes that, in order to favor openness to the other and provide parameters for the autonomous moral judgment - fundamental atitudes for the democratic cohabitation in the present complex societies -, formation cannot do without the transmission of ethical experiences of life, even if this is greatly challenges the secularized reason we have today.
\end{abstract}

\section{Keywords}

Reason - Meaning - Formation - Ethics.

I- This paper summarizes the results of a postdoctorate research The encounter of the self and the other in the school: from finding weird to understanding, conducted at the Pontifícia Universidade Católica do Rio Grande do Sul from August 2011 through July 2012, funded by CNPq. II- Pontifícia Universidade Católica do Rio Grande do Sul, Porto Alegre, RS, Brazil.

Contact: claudia.fenerich@gmail.com 


\section{Quem tentará, sequer, lidar com a juventude invocando sua experiência?}

Será possível defender, hoje, a ética, a moral e a política como dimensões, ao mesmo tempo, constitutivas da vida humana e articuladoras do processo de formação? Não será essa uma tarefa duplamente malograda nesses tempos em que não contamos com a possibilidade de fundamentar a ação humana a priori e em que nos encontramos diante de múltiplas visões de mundo, num movimento globalizado de produção voltada para o consumo e o descarte, o que gera cada vez mais riqueza para poucos e pobreza para muitos? Tais riqueza e pobreza, vale lembrar, embora remetam primeiramente às condições de sobrevivência, não se resumem nunca à esfera material, abarcando também a dimensão que podemos denominar espiritual, cultural ou simbólica.

Se, por um lado, a pretensão é um tanto desmesurada, por outro, parece suficientemente necessária. Além da ética, da moral e da política, o que mais pode direcionar a ação humana em um sentido não mercantil e alçar a existência a um patamar não natural? 0 que, além dessas dimensões, poderá ajudar-nos a enfrentar a questão sobre o que fazer, social e individualmente, com o conhecimento técnico e científico adquirido ao longo da história e intensificado a partir dos processos de desenvolvimento cognitivo propiciados pela modernidade ocidental? E qual é o sentido das conquistas cognitivas, morais e estéticas hoje computadas se isso não pode ser revertido em patrimônio de todos e se nem nos é concedida, ao menos, a possibilidade de dar um norte à formação humana?

A não ser que nos resignemos à premissa de que a história nos conduziu exatamente ao ponto de partida, ou seja, à submissão absoluta de nossas vidas a leis naturais, indiferentes à intervenção humana, é possível conceber e insistir na ideia de conferir uma orientação ética, moral e política à formação, ainda que tal tarefa remeta, hoje, ao desafio de articular a inclu- são social de todos com os projetos existenciais de indivíduos e grupos particulares sem se valer de justificativas transcendentes.

Será possível nos encontrarmos, a esta altura da história, totalmente desprovidos de saberes generalizáveis que nos permitam atribuir algum valor não mercantil às ações humanas no curso dos acontecimentos? Ou será que tememos incorrer em doutrinações ideológicas e autoritarismos ao transmitir saberes que permitem atribuir um sentido não natural e não instrumental à existência? E será justificado esse receio? Serão os saberes culturais realmente baseados em valorações éticas, tão particulares e irredutíveis a uma orientação comum? Não será uma omissão simplesmente não os transmitir?

As dificuldades com que atualmente nos deparamos para conferir à formação um caráter ético, moral e político remetem-me a uma pergunta feita por Benjamin no texto Experiência e pobreza: "quem tentará, sequer, lidar com a juventude invocando sua experiência?" (BENJAMIN, 1996, p. 114). Ninguém, responde ele nesse mesmo texto, do ano de 1933, pois reina uma pobreza de experiência e encontram-se todos emudecidos. $\mathrm{Na}$ impossibilidade de uma geração em transmitir sua experiência à outra, Benjamin vê um indício da miséria em que se situa toda uma época. Pois, ao sermos privados da capacidade de compartilhar experiências, é como se nada mais nos vinculasse ao passado, ao patrimônio cultural da humanidade, e este deixasse de ter qualquer valor. Afinal, pergunta ele, novamente: "qual o valor do patrimônio cultural, se a experiência não mais o vincula a nós?”. Quando a experiência, aquilo que nos vincula, é-nos subtraída, trata-se de "uma prova de honradez confessar nossa pobreza” (BENJAMIN, 1996, p. 115).

Como resposta ao legado de pobreza de experiência, emerge uma nova forma de barbárie: a barbárie positiva, que consiste em andar adiante, sozinho, contando apenas com os próprios recursos, criando a partir de dentro, sem olhar nem para os lados nem para trás. A 
barbárie positiva é uma reação individual, manifestada na criação estética, à miséria compartilhada por toda a humanidade. Mas será isso suficiente? Parafraseando Brecht, que afirmou ser infeliz o país que precisa de heróis: pobre da humanidade quando, para se apropriar da possibilidade de expressão que lhe é própria, depende do heroísmo criativo de alguns poucos homens capazes de confrontar a barbárie generalizada, munidos apenas de sua própria solidão.

A filosofia de Benjamin desenha dois caminhos paralelos diante da encruzilhada da perda do sentido, da dissolução dos valores éticos tradicionalmente transmitidos por meio de experiências compartilhadas entre gerações. Um aponta para trás, constituindo uma denúncia contundente da miséria presente; outro aponta para frente, realizando uma análise do potencial das manifestações artísticas e das novas formas de sensibilidade estética abertas pela técnica. Por um lado, Benjamin invoca a transmissão de saberes práticos necessários para a vida, atribuindo à experiência compartilhada, à vida comunitária, um fundamento ético; por outro, enaltece a potencialidade individual estética e investiga o alcance formativo dos produtos da indústria cultural.

Esses dois caminhos partem, entretanto, de algo comum: a constatação das profundas transformações nas relações humanas, acarretadas pelo desenvolvimento da técnica no contexto da economia capitalista e da predominância dos valores mercantis burgueses. A ambivalência da crítica não escamoteia o objetivo perseguido: resistir, de todas as formas possíveis, às condições de desvinculação com o mundo comum, de pobreza absoluta, que transformam a vida presente em renúncia, em esquecimento do sentido da experiência humana. Tal experiência, para Benjamin, diz respeito à capacidade de compartilhar e traduzir o caráter sagrado, além do natural, da vida como um todo. A vida humana, sua experiência no mundo, não pode ser explicada pelas leis naturais, tampouco se reduz às leis de uma história linear que, tendo como alvo o progresso técnico e científico, expropria a humanidade de seu patrimônio, de seus bens culturais, conduzindo à sobrevivência bruta e a uma existência enredada no mito. A linguagem é, segundo Benjamin, o lugar da experiência humana, o autêntico patrimônio da humanidade, que está ameaçado e deve ser preservado. Apartados da vida comum, sem a possibilidade de compartilhar e de comunicar experiências, encontramo-nos em meio a uma história que se naturalizou, desumanizou-se.

Se a manifestação artística individual, estética, alcança destaque no pensamento de Benjamin sobre a modernidade, não é nunca como encaminhamento de caráter subjetivo para o problema ético, mas sim como via de acesso a uma nova forma de sensibilidade que propicie uma experiência plena; como ponto de contato com o sentido da humanidade, de uma vida capaz de expressão e criação. Se o artista se torna o herói, o bárbaro que reage positivamente contra a barbárie negativa que vitimou a humanidade, é porque ele é capaz de dar forma aos conteúdos da vida comum. E se o desenvolvimento da técnica pode ser tomado como algo que propicia a emergência de uma nova sensibilidade estética, capaz de conduzir do choque à iluminação profana - apesar de, por outro lado, ser tomado como algo que acarreta a redução da experiência à vivência, ao vivido, ao imediato, condenando a vida a um movimento mítico, ao eterno retorno do mesmo -, é porque esse processo é pensado em função da necessidade de ir além da constatação das condições presentes de vida e dar uma resposta ao problema da pobreza de experiência, que se apresenta igualmente a todos.

A ética, a moral e a política constituem dimensões capazes de nos elevar além da vida orgânica, natural, da mera reprodução e da sobrevivência bruta; sua força agregadora, porém, depende do resgate da possibilidade de compartilhar experiências, da possibilidade de nos comunicarmos em uma linguagem que não se esgota no vivido, no momentâneo, na mera instrumentalização. A ética, a moral e a 
política dependem da possibilidade de atribuir um sentido pleno à experiência humana, livre das relações de poder, dominação e submissão estabelecidas historicamente. Esse sentido parece perdido entre os destroços de uma história que segue em ritmo frenético, retornando sempre para o mesmo ponto de mitificação e naturalização da vida humana, ao distanciar os homens de seu mundo comum e suprimir suas condições de vida - condições, ao mesmo tempo, materiais, expressivas e criativas.

Mas como resgatar a plenitude da experiência humana em um momento histórico de pobreza de experiência, de emudecimento? Como se valer da filosofia para isso, quando ela se compromete apenas com a instituição das possibilidades do conhecimento evidente, deixando escapar justamente a verdade, que jamais pode ser apropriada, mas somente experimentada e expressa na linguagem?

Diante dos limites impostos, em sua época, para o pensamento filosófico e com a convicção de que os rumos da história dependem sempre da possibilidade de libertar a força plena da experiência humana, Benjamin invoca a teologia. A ordem do profano tem que se erguer sobre a ideia da felicidade, e não sobre a do reino divino, diz ele em Fragmento teológico-político, de 1940, e em suas teses sobre a filosofia da história; ele acrescenta, no entanto, que a relação entre a felicidade e o elemento messiânico é um dos ensinamentos essenciais da filosofia da história. Quando a ação política trai a causa a que deve servir, é preciso arrancá-la das malhas do profano em que foi enredada (BENJAMIN, 1996). A teologia é o (alto) preço a ser pago por quem não aceita associar-se a uma concepção de história descomprometida com as condições de felicidade humana.

No presente artigo, ao enfocar a formação ética, moral e política de crianças e jovens hoje, tenho realmente a pretensão de defender a ideia de que o problema levantado por Benjamin sobre a impossibilidade de se transmitir experiência de uma geração para a outra continua ecoando e exigindo ainda uma resposta satis- fatória. Entretanto, não tenho, obviamente, a intenção de fazer isso propondo que nos disponhamos também a pagar o preço pago por ele ao enfrentar a questão em sua época. Nas atuais circunstâncias de pensamento pós-metafísico, a pesquisa em filosofia da educação, como em outras áreas, só pode progredir levando a sério a desautorização do uso de argumentos não acessíveis por uma razão secularizada. Assim, sem ferir o princípio de que tudo o que propomos deve passar pela ordem do secular, do profano (HABERMAS, 1993), buscarei apontar aqui a necessidade de perseguirmos na possibilidade de assentar a formação contemporânea sobre a base da ética, da moral e da política, afirmando a importância da transmissão de conteúdos éticos e compreendendo a invocação da teologia por Benjamin no sentido de desafiar a razão a ir além do que já conhece para dar conta da integridade da experiência humana.

É necessário considerar que hoje, apesar de defınitivamente situados em condições pós-metafísicas de pensamento que nos impedem o recurso a fundamentações a priori, bem como uma aliança com a teologia, certamente contamos, na filosofia, com aberturas não propiciadas a Benjamin em sua época. Refiro-me aqui, especificamente, ao projeto de reformulação das bases da razão moderna empreendido por Habermas, que, desde a adolescência, com a revelação da barbárie realizada pelo governo nazista, rastreia na história os

vestígios de uma razão que reconduza, sem apagar as distâncias, que una, sem reduzir o que é distinto ao mesmo denominador, que, entre estranhos, torne reconhecível o que é comum, mas deixe ao outro a sua alteridade. (HABERMAS, 1993, p. 112)

0 pensamento de Habermas nos conduz por um caminho de reconstrução das possibilidades de entendimento racional que nos afasta do projeto de Benjamin de resgatar as condições de uma experiência humana plena. Enquanto Benjamin nos convoca a escovar a história a 
contrapelo, rastreando no avesso da linearidade do tempo as motivações descartadas pela marcha do suposto progresso, Habermas nos convoca a perceber as conquistas históricas efetuadas na ordem da dominação, que resultaram em ideias jurídicas e morais baseadas em uma justiça pós-convencional, para além dos conteúdos concretos das tradições.

Para Habermas, paralelamente ao desenvolvimento da técnica, das ciências, no contexto das sociedades capitalistas, ocorreu também o desenvolvimento de uma razão autônoma em relação ao interesse por poder e dinheiro; uma razão que tem como fim o entendimento e que, enraizada nas formas de vida culturais, fluiu pelas estruturas sociais, corporificando-se no Estado de direito.

Devido às possibilidades que abre, por exemplo, para pensar a formação em termos de intersubjetividade, pela via da linguagem, a proposta de Habermas tem merecido atenção destacada na área da educação nas últimas duas décadas. No que diz respeito à ética, à moral e à política, o filósofo propicia o estabelecimento de um parâmetro para a formação: a democracia, compreendida como uma estrutura jurídica estabelecida discursivamente, ou seja, como algo que se constrói permanentemente por meio de debates públicos regulados pelas normas do direito moderno. Na democracia de Habermas, o cidadão é, ao mesmo tempo, o destinatário do direito e o legislador que cria e aplica as leis, valendo-se do medium do direito.

A partir desse pensamento faz-se possível, assim, estabelecer como objetivo da formação a competência comunicativo-discursiva para atuar na esfera pública democrática das sociedades abertas atuais. Sua filosofia sistemática e profundamente vinculada ao Aufklärung propõe e disponibiliza uma distinção bastante importante e útil entre as dimensões ética, moral e política, sem deixar de apreendê-las em conjunto na esfera da razão prática.

As questões éticas, afirma Habermas (1993, p. 99), propiciam "clareza sobre quem somos e sobre quem gostaríamos de ser”, enquanto as questões morais nos levam a compreender "o que é igualmente bom para todos". As questões políticas, por outro lado, possibilitam entendimento sobre as ações que devem ser desenvolvidas pelo Estado para promover o bem comum, garantindo a todos igual possibilidade de exercer seus direitos. A emancipação relaciona-se, dessa forma, à capacidade de entendimento e autoentendimento sobre esses três tipos de questões distintas que dependem, igualmente, da possibilidade de comunicar-se e direcionar-se por uma razão comum.

0 aporte teórico disponibilizado por Habermas constitui, sem dúvida, recurso de grande valia para pensar a formação em sentido ético, moral e político nas atuais condições de pensamento pós-metafísico. No entanto, quando temos em foco o processo de formação e perguntamos sobre o acesso aos conteúdos éticos que devem ser comunicados em relações intersubjetivas e que são necessários para alimentar os processos argumentativos no Estado democrático, deparamo-nos com o limite da comunicação nas sociedades atuais; há, além disso, a dificuldade teórica que encontramos para conferir, mesmo com Habermas, um caráter direcionador a esses conteúdos éticos.

0 entendimento sobre quem somos e gostaríamos de ser, sobre o que é igualmente bom para todos e o que deve ser feito para promover o bem comum depende da transmissão de conteúdos que apontam nesses sentidos ou da possibilidade de estabelecer razões em comum para eles? Como os conteúdos culturais, éticos e da tradição relacionam-se com a autonomia racional de sujeitos que devem se entender sobre questões que lhes dizem respeito?

Pensar essa relação que se estabelece entre a tradição e a razão em termos de retroalimentação, como propõe Habermas, é certamente algo crucial. Não menos importante, no entanto, é refletir sobre o que pode mover a comunicação entre as pessoas em uma direção que as torne aptas a se reconhecerem como igualmente humanas, igualmente competentes 
para falar, ouvir, prover material e simbolicamente sua vida individual e coletiva.

Afınal, em última instância, não é disso que se trata em uma democracia atual? 0 ganho cognitivo das sociedades abertas, racionais, não está justamente em abrir a oportunidade de problematizarmos como as tradições cumpriram ou não, até hoje, a função de propiciar aos seus integrantes o acesso à sua humanidade? Se julgamos as tradições por meio do uso da razão e se o princípio dessa razão é o estabelecimento de uma comunidade humana de reconhecimento universal, seria possível resgatar, a partir dela, a função simbólica desempenhada pela tradição que nos permite conferir um significado não fragmentado à vida, à existência? Se não podemos mais contar nem com a teologia nem com qualquer metafísica para guardar um sentido íntegro de humanidade, o que será, hoje, suficiente para nos direcionar ética, moral e politicamente?

Diante desses questionamentos, considero que, apesar de contemporaneamente contarmos com aportes filosóficos que nos propiciam uma abordagem da ética, da moral e da política sem lançar mão de recursos metafísicos - teológicos ou não -, não dispomos ainda de lastro suficiente para atribuir à formação humana o caráter ético, moral e político que sempre lhe foi próprio desde a Antiguidade ocidental ${ }^{1} \mathrm{e}$ que, mesmo hoje, à revelia da disputa empreendida pelas dimensões estética e cultural, continua sendo essencial quando temos em vista a possibilidade de conferir à cognição um caráter não instrumental e à estética um caráter, embora expressivo, não meramente individual.

No contexto de sua investigação sobre as fontes morais na modernidade, Taylor (1997) comenta que a compreensão de que nos constituímos linguisticamente não encaminha o problema experiencial, próprio também de nossa contemporaneidade, pois não oferece nenhuma garantia contra a perda da significação e da substancialidade das relações humanas. Ocultar

1- Uma análise a respeito dos fundamentos da formação na história do pensamento ocidental foi empreendida por Antônio Joaquim Severino (2006). o problema da experiência sob o do público, "como se os dois pudessem ser resolvidos ao preço de um” (TAYLOR, 1997, p. 650-651), não significa enfrentá-lo, mas tangenciá-lo.

A questão sobre a possibilidade de direcionamento da formação humana nos dias atuais deve passar, a meu ver, pelo enfrentamento do problema da experiência. A hipótese que me orienta na intenção de articular o problema do direcionamento ético, moral e político da formação com o da transmissão da experiência de vida de uma geração a outra, levantado por Benjamin, é a de que o direcionamento do processo formativo em um sentido que genericamente denominamos emancipatório depende da possibilidade de experimentá-lo e compartilhá-lo substancialmente. Ou seja, depende da possibilidade de termos algo a comunicar, a transmitir aos mais novos sobre o sentido da emancipação humana.

Como realizar isso nas atuais condições sociais de vida e de pensamento em que nos encontramos? Não ignoro que a hipótese apresentada remete também a outros problemas que precisam ser devidamente encaminhados. Tentarei aqui enfrentar alguns deles, estabelecendo um diálogo entre os pensamentos de Benjamin e Habermas no sentido de buscar articular o objetivo de uma racionalidade pública, democrática, com as fontes e os recursos indispensáveis para sua vitalização.

\section{É possível uma emancipação privada de sentido?}

Para Habermas, o materialismo semântico de Benjamin impõe a dúvida sobre a possibilidade de uma emancipação privada de sentido. Será possível que homens emancipados, em pleno exercício da razão, sejam capazes de se entender com outros na esfera pública democrática, permanecendo, contudo, "privados da luz que lhes permitiria interpretar sua própria vida com base em padrões ideais?” (HABERMAS, 1980, p. 205).

Como nota Habermas, a pergunta não poderia ser levantada por Benjamin, a quem jamais 
ocorreria tal hipótese. Para Benjamin, é impossível conceber uma emancipação que não passe pela via semântica; o que, no contexto de seu pensamento singular, implica a possibilidade de acessar a palavra nomeadora por meio da qual se revela o sentido original de humanidade inscrito no sentido da sacralidade da vida. Isso porque, no pensamento Benjamin, o sentido - universal e a-histórico - remete a uma relação plena entre homem e natureza na qual o primeiro cumpre a função de traduzir em sua linguagem a linguagem muda das coisas. Trata-se de uma hermenêutica revolucionária que tem como pretensão salvar a humanidade das teias do mito, arrancando-a de sua menoridade culpada por meio do resgate de um sentido original sagrado, cujo esquecimento implica a condenação da vida humana à mera vida, à vida naturalizada, à reprodução e à sobrevivência bruta.

0 sentido, em Benjamin, não está vinculado ao dado da tradição, mas à abertura ao infinito que esse dado tradicional propicia. A tradição não se identifica com o sentido; ela tem um caráter paradoxal e não pode ser considerada como fundamento ético. 0 sentido escapa à interpretação dada pela tradição, mas a tradição é sempre via de acesso ao sentido. Para Benjamin, é no cerne dessa relação complexa que se inscreve o papel da crítica: salvar o sentido dos mecanismos de dominação que se apoderam da tradição a partir dos próprios conteúdos expressos por ela.

Por considerar a tradição nesses termos, Benjamin imputa à sua desintegração na modernidade a emergência do problema do sentido, impensável em contextos sociais tradicionais em que este se encontrava dado explícita e imediatamente (GAGNEBIN, 1996). No entanto, por compreender que, apesar de constituir uma via de acesso ao sentido sagrado da vida, a tradição pode enredar-se no mito ao aprisionar o sentido em suas estruturas de poder, vinculando-o ao destino e impedindo o acesso à sua abertura reveladora, Benjamin afirma que é necessário salvar também a tradição do conformismo, que quer apoderar-se dela (BENJAMIN, 1996). E salvar a tradição significa salvar os bens simbólicos que ela produziu e que são patrimônio da humanidade, uma vez que estão conectados ao sentido original e não podem ser explicados apenas por seu vínculo com as instituições sociais. Toda forma de vida deve erigir-se sobre a ideia de felicidade, que é profana, mas mantém vínculos com o sentido original, sagrado. É o vínculo com o sagrado que alimenta o sentido profano de felicidade que sustenta as formas de vida. Perder esse vínculo significa cair no esquecimento, na renúncia, e enredar-se no mito.

É nessa perspectiva que se encaixa a denúncia de Benjamin sobre a decadência da experiência e que se pode compreender suas tentativas para restituir as condições de sua integridade na modernidade. É na experiência que se situa a possibilidade de transmissão e comunicação dos conteúdos tradicionais que permitem a rememoração do sentido.

Quando, nos contextos tradicionais, as experiências de vida eram comunicáveis, transmitir saberes práticos e dar conselhos eram procedimentos comuns que tinham a função não de responder a perguntas sobre o que cada um deveria fazer, mas sim de "fazer uma sugestão sobre a continuação de uma história que está sendo narrada" (BENJAMIN, 1996, p. 200). Porque possibilita a rememoração do sentido original de humanidade, permitindo um desdobramento infinito dos acontecimentos humanos significativos, a experiência é o tempo e o espaço em que se origina a emancipação; é o acesso, o medium ao sentido que a alimenta. Emancipação, para Benjamin, não significa estar além do sentido, mas retornar a ele, pois o sentido não aprisiona; ao contrário, ele liberta.

Dessa forma, a concepção benjaminiana de emancipação aponta na contramão da concepção habermasiana, na qual a emancipação resulta da conquista de uma razão autônoma em relação ao sentido. Ao formular, motivado pelo pensamento de Benjamin, a questão sobre a possibilidade de uma emancipação sem sentido, Habermas toca na carne viva da concepção de razão autônoma da qual se origina seu pen- 
samento, fazendo sangrar a ferida que lateja: afınal, o que pode realmente uma razão que não é capaz de integrar?

Diante da condição que caracteriza a modernidade - perda da possibilidade de acessar o sentido devido à desintegração das tradições e ao esgotamento da metafísica -, Habermas toma o caminho da aposta no alcance da razão procedimental, buscando, então, assentar as bases da razão na linguagem com o objetivo de desobstruir o fluxo do entendimento aprisionado na consciência subjetiva. Ao realizar esse intento propondo uma racionalidade de tipo comunicativo-discursiva, ele remete a emancipação aos processos racionais de entendimento, movidos pela lógica informal linguística. Assim, munido de uma lógica naturalizada de processos linguísticos que tendem ao entendimento, Habermas tangencia o problema do sentido, propriamente acessível por meio das tradições e das explicações metafísicas, recursos indisponíveis a nós, contemporâneos.

A questão que interessa de fato a Habermas - e que o pensamento benjaminiano traz à tona - é como a razão pode liberar-se da violência estrutural das formas de vida sem, contudo, esvaziar-se dos conteúdos éticos e morais que lhe são próprios e que constituem a fonte de energia que a alimenta. Pois, se Habermas afirma que a razão pode direcionar-se pela lógica informal da comunicação, ele não deixa de reconhecer que essa lógica depende, para se desenvolver, dos conteúdos que integram o fundo sobre o qual as interações linguísticas se destacam.

A razão habermasiana não pretende apreender o sentido, que inevitavelmente "escapa por entre os buracos da grade" (TAYLOR, 1997, p. 651) da razão moderna, por meio da qual é possível, no entanto, conhecer a realidade objetiva, estabelecer o que é correto, apreender a subjetividade; mas pretende, com certeza, tornar possível uma moralidade racional e autônoma em relação ao sentido, dotando a comunicação cotidiana - pensada nos termos da pragmática formal - de um potencial moral.
A questão, no entanto, como já mencionei na seção anterior, é que a moralidade racional, resultante de procedimentos comunicativo-discursivos que se referem a questões recortadas do fundo semântico inacessível como um todo, implica uma perda de significação e substancialidade que não pode ser subestimada, pois incide sobre a força integradora da moral, desvitalizando-a. Diante dessa perda, por mais significativo que seja para a abordagem da complexidade social atual, o paliativo da razão objetivada nas formas do direito moderno não oferece lastro suficiente para se pensar o processo de formação humana e seu direcionamento ético, moral e político. Habermas não ignora a dificuldade que se apresenta: é precisamente sobre ela que incide sua pergunta a respeito da possibilidade de uma emancipação sem sentido.

Apesar de não poderem remeter ao sentido como um todo, as práticas comunicativas contemporâneas se alimentam precisamente do "influxo daquelas energias semânticas às quais se dirige a crítica salvadora de Benjamin" (HABERMAS, 1980, p. 205). Sem essas energias, as estruturas do discurso prático perderiam sua substância. Ou seja, embora seja impossível à razão secular, profana, acessar o sentido, é dele que ela se alimenta, e sem ele não é possível conceber uma esfera pública vitalizada, uma democracia radical, como propõe Habermas. Afinal, o que pode constituir objeto de debate, questionamento e argumentação na esfera pública democrática, senão as pretensões de pessoas e grupos que se baseiam em convicções, valores, concepções de bem e de felicidade e que, por sua vez, constituem interpretações do sentido da vida, da existência? E como se forma a vontade racional autônoma, senão por meio dos debates públicos, movidos pelos conteúdos valorativos e éticos de indivíduos e grupos?

Para Habermas - que, no citado texto sobre Benjamin, situa a questão em termos de um confronto entre a liberdade propiciada pela razão moderna e a felicidade, própria da realização das formas de vida culturais, vinculando-se à perspectiva da liberdade e identificando 
Benjamin à da felicidade -, a dificuldade apenas pode ser transposta nos termos de um enriquecimento da teoria dialética do progresso.

A atualidade do pensamento de Benjamin, que "decifra a história da cultura na perspectiva da salvação para o ato revolucionário" (HABERMAS, 1980, p. 205), revela-se, portanto, na medida em que colocamos sua teoria da experiência a serviço do materialismo histórico. ${ }^{2}$ Trata-se, no pensamento benjaminiano, não de imputar à razão uma dívida que não pode ser paga, tomando o esclarecimento como uma utopia vazia, mas sim de tornar mais substancial a concepção de progresso que sustenta o esclarecimento, desafiando-a a incorporar as contradições que se interpõem entre a emancipação racional nas sociedades secularizadas e abertas e o ideal de autorrealização e de felicidade que constitui indivíduos, classes e grupos sociais, tradições culturais.

A hermenêutica de Benjamin, que conserva o sentido original da humanidade, propondo a revolução como uma apropriação instantânea desse sentido na história, pode indicar o caminho para a mudança na concepção da revolução como processo de autoformação de uma nova subjetividade.

A razão autônoma só pode promover a emancipação quando está vitalizada pelos ideais de felicidade próprios das formas de vida cultural. Afirmar a possibilidade de um esclarecimento por meio de uma razão emancipada de seus vínculos concretos e, por isso, emancipadora, uma razão que se desenvolve historicamente, apontando para um progresso social que inclui todos, implica, por outro lado, afirmar a capacidade de sujeitos dotarem sua vida de sentido, reconhecerem no outro essa mesma capacidade e se entenderem publicamente sobre o que deve ser feito para que todos possam igualmente viver de forma livre e emancipada de acordo com os ideais que projetam.

2- Isso, segundo Habermas (1980), é o contrário do propósito de Benjamin, que consistiu em colocar o materialismo a serviço de sua teoria messiânica da experiência.
Como propiciar, hoje, as condições de formação de uma subjetividade capaz de conquistar autonomia racional para negociar e se entender com outros sobre problemas éticos, morais e políticos que podem ser considerados e encaminhados de forma diversa, e, ao mesmo tempo, vincular-se a um sentido de humanidade que permita a percepção do que é comum? Como formar uma subjetividade reconhecedora de seu amplo e profundo caráter intersubjetivo?

\section{Não podemos fundar a coragem e o orgulho senão naquilo que não pode ser experimentado por nós?}

A pergunta que nomeia esta seção foi retirada de um texto de juventude de Benjamin datado de 1913, quando ele contava apenas 21 anos. Nesse texto, o autor, como ele próprio reconhece mais tarde, mobiliza suas forças contra a palavra experiência, que depois se tornaria um sustentáculo de muitas de suas teorias. 0 confronto expresso no texto resulta da constatação de que a experiência que a geração anterior à sua tem a transmitir é a da resignação e do conformismo, a do abandono dos ideais e dos sonhos de juventude, a da submissão do espírito à vulgaridade de uma vida sem horizontes. Posteriormente, com o recurso da teoria materialista, Benjamin integrará a categoria experiência à sua crítica à sociedade capitalista e aos valores burgueses. A denúncia incidirá, então, contra a pobreza de experiência que caracteriza a época moderna como um todo.

Embora inserida em um contexto teórico ainda preliminar, considero a juvenil e rebelde abordagem de Benjamin do problema da experiência pertinente para os fins deste artigo, uma vez que remete incisivamente à tensão entre espírito e experiência, ideal e realidade, sempre ressonante quando se tem em foco a formação.

A partir da questão expressa no título da seção, pretendo pensar a possibilidade de acesso ao sentido de emancipação humana por meio de experiências compartilhadas durante o processo de formação. Para isso, reproduzo a 
seguir, em um fragmento maior, a pergunta de Benjamin que norteará meu intento:

Será necessário que o objeto de nossa experiência seja sempre triste? Não podemos fundar a coragem e o sentido senão naquilo que não pode ser experimentado por nós? Nesse caso, o espírito seria livre, mas a vida o desacreditaria constantemente, porque como soma das experiências ela própria seria inconsolável. (BENJAMIN, 1984b, p. 23)

Ao conformismo e à resignação que caracterizam a experiência transmitida pela geração anterior à sua, Benjamin opõe, então, a força do espírito de sua geração, já reconhecendo, no entanto, que o desafio está em converter essa força em sentido, em conteúdo de uma nova experiência na qual o espírito se encontre integrado, e não excluído. Mesmo nesse texto, o pensador não se limita a criticar a experiência; ao constatar a privação de espírito que a caracteriza, ele é impelido a ir além, apontando a direção a ser perseguida.

0 que interessa de fato reter aqui da questão apresentada por Benjamin é que de nada adianta a liberdade infinita do espírito se a experiência concreta de vida não constituir uma abertura para o sentido do verdadeiro, do bom e do belo. É isto o que caracteriza essencialmente a vida humana, o que a distingue das demais formas de vida e pode oferecer-lhe consolo: a possibilidade de experimentar a liberdade do espírito. E a possibilidade dessa experiência de liberdade é precisamente o que deve ser transmitido de uma geração a outra, pois isso é o que realmente pode mover a história em um sentido emancipatório.

Benjamin detecta os rastros dessa possibilidade emancipatória na produção dos bens culturais, atribuindo também a eles um teor de verdade, a expressão de uma linguagem nomeadora, de um sentido original que transcende e escapa a tudo o que pode ser apreendido pelos procedimentos científicos que visam à evidência. Pois “a verdade não é um desvendamento que aniquila o segredo, mas uma revelação que lhe faz justiça” (BENJAMIN, 1984a, p. 53).

Assim como dotou as obras de arte de uma aura que as fazia aparecer, ao mesmo tempo, como acontecimento singular e transcendente, e atribuiu às histórias narradas em contextos tradicionais a possibilidade de transformar um acontecimento em algo que fosse lembrado sem limites, Benjamin pretendeu conferir às manifestações artísticas da modernidade o caráter de uma experiência exotérica ${ }^{3}$ capaz de propiciar uma iluminação profana, de fazer experimentar o lampejo da verdade.

Hoje, definitivamente, o verdadeiro, o bom e o belo não são concebidos como parâmetros absolutos, e a diversidade de interpretações sobre eles impede que os utilizemos como orientadores de nosso conhecimento e de nossa prática. Mas o fato de não podermos referir-nos a esses parâmetros de forma absoluta impede-nos realmente de fazer referência a eles? Essa impossibilidade deve, necessariamente, resultar na renúncia da geração adulta à transmissão de conteúdos orientadores da vida às gerações mais novas? Será que, nas atuais condições sociais e de pensamento em que nos encontramos, a orientação do processo de formação realmente só pode se valer das formas e dos procedimentos racionais que desenvolvemos na modernidade? Tal restrição, que, por um lado, é supostamente favorecedora da autonomia racional, não será, por outro, empobrecedora e até mesmo desvirtuadora da ideia de formação?

Em que medida a impossibilidade de compartilhar e transmitir ensinamentos orientadores das práticas de vida não nos situa, hoje, no âmago da tensão, ou melhor, da ruptura apontada por Benjamin entre liberdade do espírito e experiência concreta da vida? Se uma geração nada tem a dizer, a transmitir à outra sobre o sentido da vida, esse fato não aponta para uma falta de sentido da própria vida, restringindo-a ao âmbito de uma existência

3- Refere-se à ideia de uma experiência comum, acessível a todos, em distinção a uma experiência esotérica, restrita a um círculo de iniciados em certa teoria ou prática. 
circunstancial que se esgota sempre em si mesma, seja ela coletiva ou individualizada?

Sem dúvida, é possível conceber a existência humana como circunstancialidade, e não pretendo, aqui, desqualificar essa hipótese; mas isso implica, necessariamente, ou o abandono da ideia de formação ou seu enquadre nos termos de uma existência voltada para a realização da potência singular de cada indivíduo. Decididamente, não é esse o foco de minha pesquisa, nem, tampouco, o dos projetos de reformulação da razão moderna - entre os quais me valem aqui o de Habermas e de Taylor - que buscam potencializar, por meio da linguagem, a força integradora da moralidade, compreendendo-a como um dispositivo protetor nos processos de socialização humana (HABERMAS, 2007). Nesse sentido, as questões que aqui levanto têm como destinatários aqueles que reconhecem a orientação do processo de formação como um problema atual. A esses pergunto, ainda, se de fato consideram ser possível conceber a formação, hoje, sem fazer qualquer referência aos ideais de verdadeiro, de belo e de bom, ainda que estes não se encontrem imediatamente acessíveis e escapem, em sua totalidade, à razão comum.

Como sintetiza Taylor (1997, p. 653), o fato é que "estamos numa época em que uma ordem cósmica de significados publicamente acessível é uma impossibilidade”. Isso não significa, no entanto, nem que o sentido não esteja presente entre nós, nem que tenhamos que nos conformar com a atual impossibilidade de acessá-lo.

Seria reconfortante se pudéssemos, nas atuais circunstâncias, valer-nos tão somente da lógica dos processos comunicativo-discursivos proposta por Habermas; se ela fosse suficiente para carregar, também, na medida em que moldasse as formas do entendimento intersubjetivo, as energias semânticas que vitalizam as interações e são direcionadas na esfera pública. Porém, como isso não ocorre - e não apenas por conta da colonização da lógica comunicativa pela lógica estratégica, mas, principalmente, por conta da fragmentação que caracteriza a lógica linguística -, compreendo ser necessário aceitar o desafio de buscar meios de atribuir um sentido que faça jus tanto à vida humana como experiência não naturalizada, quanto à formação para essa experiência da vida.

Ao empreender a busca pelas fontes da moralidade e situá-las fora do self, Taylor (1997) afirma que a única maneira de que dispomos para explorar a ordem em que estamos inseridos, com esse objetivo, é por meio da ressonância pessoal, ou seja, resta-nos apreender a ordem por meio de linguagens que façam ressoar dentro do sujeito as fontes morais que estão fora dele.

A investigação de Taylor sobre a moralidade moderna desemboca, por outros caminhos, em um ponto similar ao que me conduz o diálogo estabelecido entre Benjamin e Habermas a propósito da formação hoje: a necessidade de uma vitalização da linguagem para propiciar uma experiência humana mais significativa, capaz de resgatar compromissos e "ressuscitar bens crucias para nós” (TAYLOR, 1997, p. 654). Os padrões morais básicos da modernidade, relativos a direito, justiça e benevolência, dependem de bens a que não temos acesso por meio da sensibilidade pessoal. Por isso, a busca de novas linguagens de ressonância pessoal é hoje relevante não apenas para o âmbito da experiência, mas também para encaminhar questões públicas de suma importância, como a relação que estabelecemos com o ambiente natural.

A transmissão de experiência, em Benjamin, a ideia de experiência compartilhada, que permite que o acontecimento humano não se esgote no vivido, sendo passível de ser infinitamente rememorado, é algo que se circunscreve totalmente no âmbito da linguagem, de uma linguagem comum. A teologia na qual a categoria se ancora nada tem a ver com a observância de uma lei a ser cumprida, mas com uma iluminação acessível pela sensibilidade.

0 que confere à ideia benjaminiana de experiência um caráter transcendente é o fato de ela transmitir uma sabedoria sem objeto específico, que diz respeito à vida como um todo e que permite a valoração dos acontecimentos vividos. 
0 valor do que é dito, a autoridade daquele que narra acontecimentos, conta histórias, transmite ensinamentos, compartilha experiências de vida, não se explica, em Benjamin, pela posição ocupada na hierarquia social, mas por sua utilidade na vida prática das pessoas que ouvem e recebem ensinamentos, pela pertinência daqueles conselhos às suas vidas. Essa utilidade e essa pertinência, por sua vez, não se explicam apenas pela adequação entre os conteúdos e as situações vividas, mas, principalmente, pelo fato de que os conteúdos transmitidos abrem o acesso a significações que permanecem sempre abertas, são inesgotáveis, podem ser sempre relembradas, reelaboradas.

A transmissão da experiência - quando a experiência transmitida é dotada da força do espírito, ou seja, quando toca algo grandioso e pleno de sentido (BENJAMIN, 2004) - não diz jamais respeito a uma assimilação mecânica e acrítica dos ensinamentos alheios; ao contrário, remete sempre a um trabalho intelectual pessoal sobre uma materialidade comum, a partir de uma relação intersubjetiva.

Aquele que transmite uma experiência significativa para orientar a vida de alguém é dotado de algo que não se esgota em sua subjetividade, algo que é válido para o outro, a quem compete reconhecer quando e onde tal valor deve ser atribuído. A experiência transmitida e recebida nunca é apenas subjetiva, mas transcende tanto aquele que a transmite, quanto aquele que a recebe. A transmissão da experiência confere a quem a transmite o status de locus de fontes morais (TAYLOR, 1997), que se situam fora dele, na ordem em que ele se encontra também inserido, e das quais é o enunciador, pois elas ressoam dentro dele e por meio dele encontram seu fluxo.

A transmissão da experiência requer daquele que a transmite, sobretudo, a possibilidade de conferir à sua própria experiência um caráter não subjetivo. Taylor denota uma propriedade epifânica à linguagem característica dessa transmissão de experiência que, no contexto de sua obra, é denominada ressonância pessoal da ordem. Para fazer ressonar a ordem, aquilo que é dito, enunciado, deve "colocar-nos realmente em contato com as fontes que conecta" (TAYLOR, 1997, p. 653).

Com Benjamin, vislumbramos a forma extremamente simples e direta dessa linguagem profundamente reveladora, inerente à arte de narrar; essa arte que se apoia na mão, que "intervém decisivamente com seus gestos, aprendidos na experiência do trabalho, que sustentam de cem maneiras o fluxo do que é dito" (BENJAMIN, 1996, p. 221). 0 narrador, que sabe dar conselhos não para alguns, mas para muitos, não enuncia apenas sua própria experiência, mas também a experiência alheia; "seu dom é poder contar a sua vida; sua dignidade é contá-la inteira" (BENJAMIN, 1996, p. 221).

Quem transmite uma experiência não busca o sentido, pois está nele; transmite uma moral sem medo de errar, pois sabe que "o erro é apenas um novo alento para a busca da verdade" (BENJAMIN, 2004, p. 23). Aqueles que recebem ensinamentos orientadores da vida prática certamente serão capazes, por si mesmos, de atribuir sentidos e corrigir aquilo que julgam errado. Se não receberem, no entanto, como será formada essa capacidade e como saberão julgar o que está ou não correto? De onde tirarão o alimento de suas enunciações linguísticas e por quais caminhos chegarão a constituir-se e a reconhecer-se também como locus de fontes morais?

A partir das questões que apresentei e do encaminhamento dado a elas ao longo deste artigo, quero finalizar propondo àqueles que se pretendem formadores que ofereçam, hoje e sempre, exemplos orientadores, pois, como ensina Benjamin (1996, p. 36), "nem tudo nesta vida é modelar, mas tudo é exemplar”. Proponho, ainda que, ao fazê-lo, sintam-se dignamente reconfortados, legando àqueles que se formam a difícil e importante - mas não impossível e desoladora - tarefa de realizar, por si mesmos, essa distinção crucial para suas vidas. 


\section{Referências}

BENJAMIN, Walter. Questões introdutórias de crítica do conhecimento. In: Origem do drama barroco alemão. São Paulo: Brasiliense, 1984a. p. 49-79.

. Reflexões: a criança, o brinquedo, a educação. 3. ed. São Paulo: Summus, 1984b.

. Magia e técnica, arte e política: ensaios sobre literatura e história da cultura. São Paulo: Brasiliense, 1996.

Reflexões: a criança, o brinquedo, a educação. São Paulo: Editora 34, 2004.

GAGNEBIN, Jeanne-Marie. Walter Benjamin ou a história aberta. In: BENJAMIN, Walter. Magia e técnica, arte e política: ensaios sobre literatura e história da cultura. São Paulo: Brasiliense, 1996. p. 7-19.

HABERMAS, Jürgen. Crítica conscientizante ou salvadora: a atualidade de Walter Benjamin. In: ROUANET, Sergio Paulo; FREITAG, Bárbara. Habermas: sociologia. São Paulo: Ática, 1980. p. 169-206.

. Passado como futuro. Rio de Janeiro: Tempo Brasileiro, 1993.

. Entre naturalismo e religião: estudos filosóficos. Rio de Janeiro: Tempo Brasileiro, 2007.

SEVERINO, Antônio Joaquim. A busca do sentido da formação humana: tarefa da filosofia da educação. Educação e Pesquisa, São Paulo, v. 32, n. 3, p. 619-634, set./dez. 2006.

TAYLOR, Charles. As fontes do self: a construção da identidade moderna. São Paulo: Edições Loyola, 1997.

Recebido em: 25.06.2012.

Aprovado em: 14.11.2012.

Claudia Fenerich é doutora em Educação pela Pontifícia Universidade Católica do Rio de Janeiro. 